\title{
(Re)Pensar a cultura e a formação em contexto de trabalho: tendências, perspectivas e possibilidades de articulação'
}

LEONOR MARIA DE UMA TORRES*

\section{Introdução}

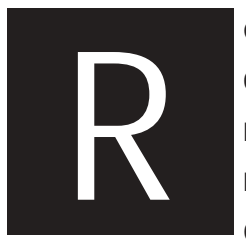

epresentando dois campos temáticos estruturantes da Sociologia das 0 rganizações, a cultura e a formação instituíram-se como objectos de investigação em permanente reconceptualização, sobretudo a partir do último quartel do século XX. Referenciadas a quadrosteórico-conceptuais de abrangência pluriparadigmática, as duas problemáticas sofreram evoluções paralelas, algo simétricas, mas de natureza muito auto-centrada, raramente ensaiando articulações e cruzamentos entre as suas valências heurísticas. Apesar de este fechamento do campo temático ter proporcionado uma significativa solidez teórica no interior de cada um dos domínios, não deixou de acarretar como consequência pelo menos dois tipos de fenómenos: uma insularização dos objectos de estudo, artificialmente desgarrados dos seus contextos de produção e, por conseguinte, uma maior permeabilidade à penetração de ideologias, racionalidades e valores de feição tecnocrática. A sobrefocagem nas dimensões intrínsecas da formação e da cultura, em desconexão com todo um quadro de referenciação político-

\footnotetext{
* Assistente no Departamento de Sociologia da Educação e Administração Educacional do Instituto de Educação e Psicologia da U niversidade de M inho. E-mail: leonort@ iep.uminho.pt

10 s editores optaram por manter a ortografia original do Português (de Portugal).
} 
ideológico a partir do qual seria possível problematizar as potencialidades de ambos os campos, proporcionou a adopção de perspectivas mais tecnicistas, pragmáticas e gestionárias na análise dos fenómenos culturais e dos processos formativos em contexto organizacional.

A aparente despolitização inerente a muitas das abordagens culturais e da formação, sobretudo aquelas que as tomam como meros instrumentos técnicos de gestão quotidiana, acaba por se revelar uma realidade hiperpolitizada, na justa medida em que passa a estar ao serviço de uma supraracionalidade económica dominada pelos valores da eficiência, da eficácia e da competitividade (Lima, 1994). E é neste sentido que alguns estudos ensaiam uma articulação entre a cultura e a formação, defendendo uma forma de articulação excepcionalmente funcional, baseada numa relação linear e unidireccional entre a segunda (formação) e a primeira (cultura), isto é, à formação profissional dos trabalhadoresé atribuído um papel central na difusão e reforço da cultura e da identidade organizacionais.

Neste seguimento, os objectos cultura e formação tendem a erigir-se em técnicas estrategicamente accionadas para responder aostão propalados imperativos da globalização económico-cultural, transformando-se, consequentemente, em relevantes instrumentos de gestão ao serviço de uma pressuposta melhoria dos níveis de desenvolvimento económico e, mesmo, de promoção dos valores de cidadania democrática. Por isso, consideramos pertinente a deslocação do enfoque analítico muito determinado pelos valores da eficácia, da excelência e da performance para uma outra abordagem que privilegie um olhar sobre as políticas e as práticas de formação à luz das especificidades culturais e identitárias das organizações. 0 que procuramos propor com este trabalho é uma tentativa de relocalização do debate em torno desta problemática, favorecendo o regresso ao estudo das especificidades dos diversos contextos sócio-organizacionais, que na nossa óptica parece ter sido preterido por abordagens mais recentes inspiradas em lógicas emergentes de uma ordem mais global ou mega-analítica, 
externa e, de certo modo, determinista. Parece-nos que esta inversão metodológica e analítica, sem no entanto deixar de olhar para aquelas condicionantes externas, nospermite, ainda que de forma muito exploratória, senão desocultar pelo menos apontar algumas das funções político-ideológicas inerentes ao processo de formação no contexto de trabalho.

Assim, a análise das diferentes manifestações da cultura em contexto organizacional (e.g. perspectivas integradora, diferenciadora e fragmentadora) ${ }^{2}$ quando cruzada com a diversidade de políticas e práticas de formação, poderá, em nosso entender, contribuir para relançar o debate em torno de questões mais voltadas para as especificidades organizacionais, nomeadamente as que se reportam à realidade portuguesa. Por conseguinte, interessará analisar criticamente de que modo a cultura e a identidade organizacionais poderão ou não constituir um factor que ora reforça ora fragiliza as opções relativas às políticas de formação, so bretudo quando nos parece necessário compreender os discursos apologéticos da formação e da cultura frequentemente produzidos e os sentidos das práticas nos vários contextos organizacionais, onde, por vezes, se contradizem e tendem a evidenciar a vertente mais instrumental e gestionária da sua articulação.

$\mathrm{Na}$ segunda parte deste trabalho, analisaremos alguns dados empíricos sobre as políticas e práticas de formação recolhidos numa organização empresarial do distrito de Braga e procuraremos debater a natureza das relações estabelecidas entre a cultura e as identidades organizacionaise a construção das políticas de formação. Trata-se, fundamentalmente, de compreender, numa lógica de estudo de caso, a forma como a problemática da cultura e identidade de determinada organização constitui ou não um factor condicionador da formulação das políticas de formação.

2 Para uma síntese das principais focalizações da problemática da cultura organizacional, remetemos o leitor para os nossos trabalhos (Torres, 1997, 2004) onde debatemos as várias correntese perspectivas teóricas em confronto, apoiados nos trabalhos centrais desenvolvidos por Smircich (1983), Schein (1985), M artin e M eyerson (1988), Frost (1991), M artin (1992, 2002), Alvesson e Berg (1992), Alvesson (2002). 


\section{Focalizações teóricas da cultura organizacional e sentidos da formação}

\subsection{Perspectiva Integradora e Dinâmica Formativa da Socialização Profissional}

Inspirada nos enfoques mais funcionalistas, que conceptualizam a cultura organizacional como uma variável estrutural (dependente e/ou independente), a perspectiva integradora privilegia os aspectos mais consensuais da cultura, sendo esta tanto mais forte e consensual quanto mais alargad o for o seu grau de partilha entre os trabalhadores da organização. Estaríamos, então, em presença de uma organização que tem uma cultura no sentido possessivo do termo, isto é, a cultura é entendida como algo de objectivo e como pertencendo à ordem interna e específica da organização. No fundo, reduz-se a um conjunto de símbolos, crenças, valores, mitos e outros factores pertencentes à ordem do simbólico, que representam o padrão da conformidade ideal e que, por isso, se deseja interiorizar (ou inculcar) prioritariamente a todos os actores da organização. 0 protagonista cultural, ou o elemento central na criação da cultura é o líder (fundador ou empresário) da organização, que adquire poderes de eleger os seus próprios valores e crenças como aqueles que passarão a ser impostos aos restantes membros da organização. Sendo a cultura vista como uma variável que a organização tem e que se pode desenvolver à luz dos interesses gestionários, abre-se então a possibilidade, segundo esta perspectiva, de gerir e mudar a cultura a favor da integração, da comunhão da interesses, da partilha de valores, do consenso. Não será de estranhar, por isso, que os mecanismos eleitos para salvaguardar a manutenção e a consolidação do status quo e da estabilidade cultural sejam os processos de socialização profissional, as estratégias de treinamento do pessoal, os rituais de confraternização, os mitos da grande família, etc. Como expoentes máximos do desenvolvimento destes pressupostos teórico-conceptuais, situam-se os 
autores Edgar Schein (1985, 1991), William O uchi (1986) e T. Peters e R. Waterman (1987), entre outros.

Assim, e procurando sintetizar estes pressupostos no aludido trabalho por nós produzido, à luz da perspectiva integradora (Schein, 1985, 1991; Mcdonald, 1991; Barley, 1991, entre outros)

[... ] a cultura é caracterizada pela consistência, clareza e consensualidade de valores, interpretações e crenças partilhadas pelos membros de uma organização. $\mathrm{Na}$ esteira da corrente funcionalista, ignora-se a possibilidade de emergência de eventuais inconsistências, conflitos, ambiguidades ou até de diferenciações entre subculturas, na medida em que se pressupõe uma análise focalizada no plano dos 'consensos' da organização. A existência de conflitos organizacionais apenas poderá ser admitida para se argumentar e fundamentar a ausência de cultura organizacional (Torres, p.4041,1997).

O ra, se estamos em presença de uma organização claramente orientada segundo moldes culturais integradores, cuja perpetuação e preservação é assegurada através de um processo contínuo de socialização dos novos e actuais membros, então a perspectivação da formação face a este quadro parece-nos suscitar uma dupla interrogação: fará sentido uma política de formação no sentido formal, escolarizado e descontextualizado quando as trajectórias profissionais dos actores estão profundamente enraizadas em valorese crenças consensualmente partilhadas desde o topo (gestionário) à base operativa? Não terão as mudanças nas práticas e desempenhos profissionais que ser repensadas a partir de novos e renovados contextos de socialização e de aprendizagem organizacional e cultural dos actores nas suas diversas situações de trabalho? U m pouco na esteira de Dubar (1985, 1991) e de Lesne e M ynvielle (1990) a propósito das suas reflexões em torno da formação e da socialização, pensamos que as démarches de for- 
mação em contextos organizacionais muito marcados pela integração simbólico-cultural tendem a confundir-se com as próprias interacções vividas em situação de trabalho.

Pelo atrás exposto, parece desenhar-se quer um processo de mútuo reforço entre cultura e formação quer uma tendência para uma certa fusão entre os dois objectos de análise ${ }^{3}$, sendo que ambos poderão constituir uma dupla e imbatível estratégia de gestão para a eficácia e excelência organizacionais. Quer num caso quer noutro faria todo o sentido que a política de formação desenvolvida derivasse de um processo organizacionalmente construido, isto é, não dependente dos pacotese das ofertas de formação (e de formadores) por catálogo.

U ma segunda interrogação que nos assalta diz respeito ao modo de compatibilização entre esta lógica de formação informal que se processa nos contextos de trabalho e a necessidade presente em algumas organizações próximas deste ideal-tipo de desenvolverem e actualizarem também (pelo menos em alguns grupos de trabalhadores) conhecimentos e competências teóricas e técnicas mais ou menos especializadas em determinados domínios do trabalho. Independentemente da existência de um processo de socialização profissional convergente com os grandes objectivos organizacionais, das estratégias de formação do pessoal mais ou menos informais, dos rituais de confraternização, dos mitos da grande família, não podemos escamotear as diferenciações profissionais ao nível das especializações técnicas. Sendo que algumas destas poderão requerer formações mais formais e saberes mais técnicos, a questão que então se coloca é a de compatibilização entre uma lógica formativa mais técnica e outra, por sinal, a estruturadora do ethos e da identidade da organização, mais comportamental, mais socializadora. Parece-nos tratar-se de um exercício interessante e desafiador para ensaiar na prática profissional e gestionária. 


\subsection{A Perspectiva Diferenciadora e as Micropolíticas de Formação}

No tocante a esta perspectiva, salientamos sobretudo a ênfase colocada nas diferenciações culturais, nos dissensos, nos conflitos e nos antagonismos culturais emergentes numa mesma organização. A organização caracteriza-se pela coexistência (simultânea ou não) de diferentes subculturas cujo desenvolvimento e cristalização radica na segmentação da organização do trabalho contemporâneo - a divisão vertical e horizontal, a departamentalização, a existência de vários postos de trabalho - que ao permitir o estabelecimento de interacções privilegiadas no espaço e no tempo entre determinados grupos profissionais, lança as condições para a emergência de múltiplas (sub)culturas, tornando-se mesmo difícil identificar as suas fronteiras, o seu grau de infiltração e extensão. Nesta óptica, a cultura organizacional corresponderia ao denominador comum das várias subculturas existentes com a particularidade de nunca ser conceptualizada de forma homogeneizante, até porque parte-se do princípio de que as diferenciações sociais e culturais são inerentes ao sistema social como um todo.

Com grande popularidade nas décadas de oitenta e noventa (Gregory, 1983; Maanen, 1991; Rosen, 1991, entre muitos outros), esta perspectiva vê a cultura organizacional como "[...] um amálgama de subculturas diferenciadas que emergem num contexto particular. A partilha de idéias e valores só se torna clara quando referenciada à respectiva subcultura. Ambiguidades e inconsistências só aparecem na intercepção das diferentes subculturas" (Torres, p.43, 1997).

Contrariamente à perspectiva anterior, a perspectiva diferenciadora atribui um papel de protagonismo aos actores no processo de construção e reconstrução da cultura da organização, pois visibiliza o papel activo e determinante dos diferentes grupos profissionais na negociação dos significados, valores, normas estruturadores da organização. Aproxima-se, portanto, de um enfoque mais interpretativo. 
Eé por referência a estas subculturas que segmentam culturalmente a organização que podemos perspectivar diferentes dinâmicas na construção das identidades profissionais, muito sedimentadas nas vivências e nas interacções regulares estabelecidas entre o grupo de pares que se confinam às mesmas condições de trabalho. Não admitindo a presença de uma cultura homogeneizante que dilua as heterogeneidades profissionais, esta visão teórica faz ressaltar as implicações dos processos de aprendizagem cultural na construção dasidentidades colectivas de trabalho, aliás uma agenda teórica sustentada por Sainsaulieu $(1987,1988)$.

$0 \mathrm{ra}$, atendendo às especificidades de um contexto organizativo marcado por uma multiplicidade, por vezes conflituosa, de loci de cultura ou meios portadores de cultura (culture bearing milieu) ${ }^{4}$ e que visibiliza o papel activo e determinante dos grupos sócio-profissionais na negociação dos significados, valores, normas estruturadoras da organização, somos tentadas a lançar um renovado olhar sobre as lógicas e as práticas de formação. 0 reconhecimento de que em contexto organizacional coexistem subculturas ocupacionais sedimentadoras de identidades profissionais diversas parece implicar a aceitação do princípio da diversidade também ao nível das políticas de formação. Senão vejamos: as apropriações das situações de trabalho feitas pelos trabalhadores e os sentidos subjectivos que Ihes são conferidos, ao configurarem diversas formas identitárias, condicionam também as suas concepções e práticas de formação. As diferentes representações, expectativas e sentidos conferidos pelos actores a todo o processo de formação estão condicionados pelo seu grau de pertença e integração em determina-

4 M eryl R. Louis (1985) distingue quatro loci de cultura: o primeiro, situado ao nível infra-organizacional, é desenvolvido estrategicamente a partir do topo da organização (da coligação do poder) e poderá ser difundido para o interior ou exterior da mesma (versão também conhecida por corporate culture); o segundo locussitua-se ao nível vertical, por exemplo ao nível de um departamento; 0 terceiro, situado num plano horizontal, pode estender-se a qualquer categoria profissional (com mesmo tipo de funções e ao mesmo nível hierárquico); finalmente, o quarto situar-se-ia ao nível transorganizacional, atravessando e influenciando, assim, várias organizações. 
da subcultura ou forma identitária. Isto é, "[... a cada forma identitária, associada a um "mundo vivido no trabalho", corresponde, de forma ideal, um tipo de formação, isto é, um sistema de objectivos, de métodos pedagógicos e de organização prática"(Dubar, p.50-51, 1997).

Partindo do postulado gestionário de que a formação deve ter efeitos positivos ou eficazes ao nível do desempenho profissional dos trabalhadores, a ideia de resistência à mudança (ou à formação), sobretudo quando se desenvolve uma política formativa do género monolítico (quanto aos objectivos, método e organização) parece constituir, aqui, uma verdadeira ameaça. Q ualquer fórmula pretensamente ideal de formação, num contexto destes, só o é para o grupo de actores cujos referenciais simbólicoculturais se identifiquem com tais pressupostos. Constituirá para os restantes subgrupos de trabalhadores, muito provavelmente, uma forma de deslegitimação e desestruturação dos seus elos identitários, podendo gerar, por conseguinte, sucessivos comportamentos de alheamento e resistência à formação. Daí a nossa opção pela defesa não de um modelo hegemónico e uniformizante de formação mas pela construção contextual de micropolíticas de formação mediatizadas pelas especificidades culturais e identitárias dos grupos sócio-profissionais coexistentes na organização. Em termos mais operacionais, estaríamos em presença de vários modelos de formação ao nível dos saberes, dos objectivos, dos métodos, da organização, da avaliação, entre outros.

\section{U ma cultura da formação ou uma formação na e pela cultura?}

Atendendo à possibilidade de coexistirem, num mesmo contexto organizativo, formas culturais integradoras e diferenciadoras, e admitindose teoricamente a predominância de uma sobre as outras, somos tentados a contemplar diferentes modos de perspectivação sobre o objecto forma- 
ção. Este posicionamento conduz-nos à assunção de uma estratégia de formação endogenamente construída e reconstruída por referência aos diversos contextos culturais e identitários que, à partida, poderão condicionar a sua própria démarche. Evidentemente que esta inspiração cultural e identitária subjacente à concepção de políticas de formação pode assumir uma dupla função, se pensarmos que elas poderão estar ao serviço das estratégias e dos objectivos da organização. Como forma legitimadora do statu quo organizacional, o projecto de formação desenvolver-se-ia, desde a sua concepção à avaliação, em consonância com o ambiente cultural, constituindo, mesmo, um reforço importante dos seus traços identitários. Tratar-se-ia de um projecto multidireccional que contemplasse diferentes formas de expressão e formalização ( $C$ f. síntese apresentada no quadro 1) consoante se dirigisse a grupos de actores inseridos em contextos culturais e identitários potencialmente mais integradores ou diferenciadores.

Q uadro 1. M Manifestações da Cultura, Identidades e Concepções de Formação em Contextos 0 rganizacionais

\begin{tabular}{l|l|l|l}
\hline $\begin{array}{l}\text { Perspectivas } \\
\text { de Análise }\end{array}$ & $\begin{array}{l}\text { Tipo de } \\
\text { Identidade }\end{array}$ & $\begin{array}{l}\text { Concepção } \\
\text { de Formação }\end{array}$ & $\begin{array}{l}\text { Formalização } \\
\text { da Formação }\end{array}$ \\
\hline $\begin{array}{l}\text { Perspectiva } \\
\text { Integradora }\end{array}$ & $\begin{array}{l}\text { Identidade } \\
\text { Organizacional }\end{array}$ & $\begin{array}{l}\text { Formação/Socialização } \\
\text { no local de trabalho }\end{array}$ & $\begin{array}{l}\text { Projecto de } \\
\text { Formação/Empresa }\end{array}$ \\
$\begin{array}{l}\text { Perspectiva } \\
\text { Diferenciadora } \\
\text { Ie Formação }\end{array}$ & $\begin{array}{l}\text { Identidades } \\
\text { Sócio-Profissionais }\end{array}$ & $\begin{array}{l}\text { Subprojectos } \\
\text { de Formação }\end{array}$ \\
\hline
\end{tabular}

Fonte: TORRES, Leonor L. A Cultura O rganizacional na (Re)conceptualização da Formação em Contextos Organizacionais, Cadernos de Ciências Sociais, nos 21-22, pp. 145, 2001. 
Por outro lado, olhando o projecto de formação como um factor gerador de mudanças ou de reestruturações nos contextos culturaise identitários, apontaríamos para uma trajectória mais complexa e de efeitos mais incertos, desde o nível da concepção ao da avaliação, desde logo devido ao facto de as ordensculturais e identitárias assentarem em lógicas construtivas e reconstrutivas dificilmente abaláveis (ou modificáveis) através de um processo exclusivamente formativo. Esta questão levar-nos-ia a debater, uma vez mais, a possibilidade de mudança e de gestão da ou pela cultura da organização. ${ }^{5}$

No seguimento desta trajectória de análise sobre as relações entre cultura e formação, e arriscando uma idéia potencialmente controversa, parece-nosque a(s) problemática(s) da cultura e da identidade organizacionais constitui(em) um imprescindível enquadramento para a construção de estratégias de formação, muito embora perspectivemos a sua função como essencialmente inspiradora ou reveladora de toda uma pluralidade de formas de formação possíveis, por referência também à possibilidade da sua tripla manifestação cultural.

N este sentido, conceptualizamos o processo de formação como uma dimensão inscrita na dinâmica cultural da organização, uma espécie de variável dependente, conectada com o quadro axiológico-normativo da organização e a sua diferente apropriação por parte de indivíduos e/ou de grupos em contexto de trabalho. Não se refuta liminarmente o papel da formação no reforço da cultura e correlativamente da identidade organizacional como estratégia de enfrentamento dos desafios advindos de eventuais mudanças sócio-organizacionais (ou outras). A nossa agenda teórica conduz-nos, no entanto, ao afastamento da função meramente ritualista e gestionária (no sentido manipulativo) que lhe possa ser atribuída, sobretudo quando objectivada como uma imposição, para cumprir essencialmente

5 Para uma análise mais aprofundada sobre a problemática da mudança da cultura, veja-se entre outros, os trabalhos de 0 ttaway (1982) e de Gomes (1994). 
estratégias de suprimento de capital, e alheia às disposições culturais e identitárias dos actores e dos grupos organizacionalmente referenciados. É por isso que quando referimos os valores da eficácia, da eficiência, da excelência, da qualidade, entre outros, o nosso posicionamento é não refutarmos a sua validade como metas pertinentes na gestão empresarial da actualidade. A nossa problematização faz sentido quando tais valores são obnubilados na retórica produzida sobre a eventual correlação entre formação e cultura, pretendendo-se fazer crer que estas são as principais preocupações na definição das estratégias empresariais. Arriscamos, assim, sugerir uma formação nas e pelas culturas, em vez da fórmula clássica que enfatiza a cultura da formação.

\section{A cultura e a formação debatida a partir de um caso em estudo}

No âmbito de um projecto transnacional de investigação financiado pela Comissão Européia (Programa Leonardo Da Vinci) intitulado Políticase Práticas de Formação em Contextos O rganizacionais ${ }^{6}$, procedeu-se ao de-

60 projecto de investigação Políticase Práticas de Formação em ContextosO rganizacionais(Trappo Training Policies and Practices in O rganisations) desenvolvido no âmbito do Programa Leonardo Da Vinci e financiado pela Comissão Européia integrou entre 2000 e 2003 três equipas de investigação: uma equipa promotora constituída pelo coordenador Prof. Doutor Carlos V. Estevão, por dois docentes/investigadores do Departamento de Sociologia da Educação e Administração Educacional do Instituto de Educação e Psicologia da U niversidade do M inho, e três investigadores da TecM inho Associação U niversidade Empresa para o Desenvolvimento (Guimarães, Portugal); e duas equipas parceiras convidadas, uma da Universidade de Jonkoping (Suécia), coordenada pelo Professor Benny H jern e outra da U niversité Pierre M endés France, de Grenoble (França), coordenada pelo Professor G. Figari. No contexto da temática genérica Políticas e Práticas de Formação, a equipa do projecto elegeu para estudo mais aprofundado quatro linhas de investigação: 1) Cultura e Identidades 0 rganizacionais; 2) Cidadania O rganizacional; 3) Redes O rganizacionais e Profissionais; 4) Pilotagem das Políticas de Formação. 0 trabalho que agora apresentamos integra-se na primeira linha de investigação - Cultura e Identidades O rganizacionais. Entre os diversos trabalhos publicados no âmbito deste Projecto, consultar Estevão (1999), Torres (2001) e Estevão (Coord.) (2002). 
senvolvimento de seis estudos de caso em organizações empresariais do norte de Portugal. Para este trabalho, elegemos um dos estudos desenvolvidos numa das empresas (empresa E) onde foram recolhidos numerosos documentos (Plano Anual de Formação, Balanço Social, Jornais publicados, entre outros), realizadas diversas entrevistas a actores privilegiad os e onde se procedeu igualmente à administração de um inquérito por questionário a uma amostra de 131 trabalhadores. Com base na análise e interpretação de toda esta diversidade de dados empíricos recolhidos, procuramos debater a nossa agenda teórica a partir das seguintes rubricas.

\subsection{O perfil da empresa $E$}

A empresa E é uma empresa electrónica sediada em Portugal desde o início de 1990. Esta empresa conta com os serviços de diversas empresas, negócios e instituições, abrangendo, directa ou indirectamente, cerca de 25.000 pessoas. Pertencente ao grupo Bosh desde 1923, possuía em 2001, 2200 trabalhadores.

U m dado relevante sobre o perfil social dos trabalhadores prende-se com o facto de cerca de $70 \%$ serem do sexo feminino e de mais de $50 \%$ dos trabalhadores (homens e mulheres) se situarem numa faixa etária compreendida entre os 18 e os 34 anos de idade. Por outro lado, importa verificar que a maioria destes trabalhadores (63\% homense $73 \%$ mulheres) trabalha na empresa há mais de 5 anose possuem um contrato permanente $(78 \%)$. Em relação ao perfil escolar, constatamos que uma percentagem significativa dos trabalhadores possui apenas o 10 ciclo (39\%) e o 2 ㅇccico (26\%) do ensino básico, mas quando cruzamos esta variável com a variável sexo, verificamos que as mulheres detêm, regra geral, uma escolaridade bastante mais baixa do que os homens. Talvez por isso também ocupem funções menos qualificadas dentro da empresa, já que a maioria das trabaIhadoras pertencem às categorias de profissionais semiqualificadose prati- 
cantes/aprendizes. A quase totalidade dos trabalhadores da empresa reside em Braga'.

Por fim, do ponto de vista formal, a estrutura organizativa da empresa E é centralizada, vertical e, no entender dos vários entrevistados, bastante hierárquica, no sentido de todos os cargos estarem bem definidos relativamente às suas funções e aos seus poderes:

Há vários níveis hierárquicos, há vários fóruns de decisão, há várias reuniões onde se discute onde se decide. Mas para mim muitas vezeso processo de tomada de decisõesé difícil de compreender, é confuso, por vezes até o próprio processo de encaminhar um assunto para uma tomada de decisão, por vezesé complexo. 0 que quer dizer que, não estão perfeitamente definidos os mecanismos de tomada de decisão (Excerto de entrevista realizada em 2001 a um chefe de secção).

Há uma hierarquia bem definida, há um chefe de cada secção, toda a gente sabe quem éo chefe da secção. Ele é que coordena as actividades dentro da secção e as pessoas com ele desenvolvem... Claro que, não há aquela hierarquia que o chefe de secção não pode falar com as operárias, tem que primeiro falar com o chefe de linha não, ou o chefe de fábrica não pode falar com uma operária tem que falar primeiro com o chefe de secção, pedir autorização depois com o chefe de linha, depois falam com o chefe, isso já não existe hoje em dia, esses curtos circuitos quer sejam para cima, quer seja para baixo são, já ninguém liga (Excerto de entrevista realizada em 2001 ao responsável pela mini-fábrica de Vila Real).

De igual forma, o organograma contempla distintas funções (directivas, de administração, de chefia), nomeadamente ao nível dos departamentos, 
das secções, das linhas de produção. O D epartamento de Recursos Humanos (DRH ) é composto por um Director e nove trabalhadores, responsáveis por diferentes áreas (secretariado/apoio administrativo, formação, processo de melhoria contínua, avaliação do desempenho, jornal, entre outras).

4.2. Princípios, valorese orientações da empresa E: a cultura unificadora idealizada e as subculturas periféricas praticadas

Q uando procuramos identificar os principais valores e orientações da empresa $E$, confrontamo-nos, desde logo, com dois registos relativamente distintos: o primeiro, situado num plano maisformal e gestionário, presente em vários documentos da empresa (jornal $O$ Ponto, conferência escrita apresentada pelo Director do Departamento de D esenvolvimento e Formação de Recursos H umanos (MEF) e outros documentos dispersos) apela aos valores da qualidade, da produtividade, da excelência, da eficiência, da eficácia e da inovação. 0 objectivo estratégico da empresa, do ponto de vista da sua administração, seria o de elevar a produtividade com acréscimos também da qualidade dos produtosfabricados. De um ponto de vista mais operacional, procura-se apelar à importância conferida à capacidade de inovação, à rotatividade, à flexibilidade, à polivalência, à mudança e à autonomia, como valores centrais a difundir no local de trabalho. No entanto, esta nova filosofia de trabaIho - muito associada à ultima administração - tem esbarrado com culturas e identidades de trabalho assentes em valores e atitudes mais rígidas, mais fechadas e, portanto, mais resistentes às mudanças preconizadas. Por exemplo, na perspectiva do Director do DRH predomina ainda uma cultura taylorista e muito hierárquica, de máquina, baseada no controlo burocrático e na especialização do saber (e da função), não permitindo a construção de uma visão global, integradora e identitária da organização:

[... ] temos aqui ainda, esta visão de empresa/fábrica que a empresa deve funcionar como uma máquina, cada 
um precisa de disciplina só para cumprir as suastarefas. Lentamente estamos a tentar mudar esta visão, na direç̧ão de um organismo que pode também adaptarse, que pode crescer, que é sensível ao seu mundo exterior também. Tivemos um taylorismo enorme de sentido de uma hierarquia muito forte. Aqui como no estrangeiro vou dizer duas coisas, cultura portuguesa é hierárquica, como as culturas do norte, e também Bosch é uma empresa com tradição que tem muitos regulamentos e procedimentos, que antes acreditavam nesta visão da máquina. Então, estes dois factores contribuem para muita disciplina, outros diria muita burocracia e muita rigidez. Nós temos que mudar isto mas, não é de um dia para outro mas passo a passo, lentamente, formando as pessoas, qualificando as pessoas e dandoIhes a responsabilidade para o seu próprio sítio de trabalho. É uma cultura de mudança. E lentamente, acho que estamos a caminhar no terreno (Excerto de entrevista realizada em 2001 ao responsável pela Formação e Melhoria Contínua).

H ierarquia aqui é muito importante, status aqui é muito importante aqui, está a mudar, é interessante aqui, somos uma multinacional de cultura alemã onde há menos distância entre as hierarquias e a cultura, em Portugal há uma diferença bastante grande. Muitos chefesaqui gostam de privilégios, que sejam pequenos como estacionaro carro aqui dentro. Por exemplo, houve um escândalo, um dia eu vim aqui e estacionei a minha bicicleta aqui dentro, porque sou chefe de departamento tenho direito de estacionar o meu carro mas, estacionei a bicicleta, isto foi...(risos). A hierarquia bloqueia demasiado aqui, as pessoas têm que pedir permissão para cada coisa (Excerto de entrevista realizada em 2001 ao responsável pela Formação e Melhoria Contínua). 
De resto, ainda predomina uma visão conflituosa, de tipo sindicalista, por parte dos trabalhadores em relação à administração, no sentido em que adoptam uma atitute de confronto, de crítica e não de colaboração mútua no projecto da empresa, no sentido em que ainda não se criaram condições de participação dos trabalhadores nas várias esferas da empresa. A este propósito o responsável pela Formação e Melhoria Contínua é bastante explícito quando refere que

A comissão de trabalhadores aqui, gosta de criticar, dizer o que não está bem mas, às vezes, quando tentamosfazê-la entrar no processo para construir algo novo eles não gostam disto, é o modelo de conflito, eles estão acostumados e alguns dos nossos chefes também (Excerto de entrevista realizada em 2001 ao responsável pela Formação e Melhoria Contínua).

Talvez, por isso, haja quem defenda a idéia de que os trabalhadores desta empresa, apesar de se identificarem genericamente com a política da empresa (por exemplo, cerca de $70 \%$ dos inquiridos refere que se apresenta profissionalmente invocando o nome da empresa e não o nome da profissão ${ }^{8}$ ), ainda mantêm com ela uma relação instrumental, muito ligada ao vencimento. Aliás, na perspectiva do responsável da Formação e M elhoria Contínua, os portugueses em geral e os trabalhadores da empresa $\mathrm{E}$, em particular, não têm uma relação com o mundo do trabalho (a empresa) de grande envolvimento:

Falando de cultura [... ] osalemães e estrangeiros fazem menos a diferença entre a vida pessoal e profissional porque, a vida profissional tem evoluído de modo muito importante à vida pessoal. Estamos em Portugal, [... ] os portugueses, vão dizer que os alemães vêm e se vão

8 Resultados do inquérito por questionário administrado a uma amostra de 131 trabalhadores da empresa $\mathrm{E}$, no ano de 2001. 
de novo, não há essa identificação esse engagement com a empresa, não vêem que nós vivemos para esta empresa, nós vivemos pelo grupo Bosch. O grupo Bosch influi a primeira língua do meu filho, se eu for do grupo Bosch fala o meu filho uma língua estrangeira, melhor do que a minha língua, eles não têm esta dedicação que nós temos com a empresa eles vêem uma empresa como [nome da empresa E] - Portugal e nós vemos a empresa como Bosch-M undial (Excerto de entrevista realizada em 2001 ao responsável pela Formação e Melhoria Contínua).

Por outro lado, encontramos indicadores, sobretudo ao nível das entrevistas, da coexistência de diferentes subculturas e identidades profissionais (que ostentam diferentes visões do trabalho e da empresa) aos níveis dos diversos Departamentos. Por exemplo o testemunho apresentado por um chefe de secção é bastante elucidativo a este propósito:

Q uer dizer, há um entendimento de que cada departamento tem uma visão própria da missão e do sistema de valores que não é comum à empresa toda. Portanto, existe essa segmentação de departamentos, existe essa visão por vezes diferente de departamento para departamento. E como resultado disso o trabalho em equipa, que é absolutamente indispensável para resolver alguns problemas, ressente-se altamente, por causa dessas visões diferentes. Este problema está identificado, penso eu, em toda a empresa, desde a direcção, a administração até aosníveis de chefia intermédios estão conscientes, mas é algo que está enraizado e vai levar o seu tempo a ser verificado (Excerto de entrevista realizada em 2001 a um chefe de secção).

Por fim, uma referência final a alguns eventos de natureza recreativocultural e desportiva que, pela quantidade e qualidade, merecem destaque: o jornal $O$ Ponto, como tentativa de divulgação de informação sobre 
um conjunto de acontecimentos. As festas de $\mathrm{N}$ atal, os passeios periódicos, os concursos, as actividades desportivas, constituem apenas alguns exemplos de como se tem procurado criar contextos de interação social muito propícios à transmissão dos valores centrais da organização.

4.3. O sobjectivos da política de formação da empresa: da retórica de uma verdadeira revolução cultural à prática de uma formação meramente tecnicista

Face a um quadro marcado por diferenciações culturais e identitárias, a formação profissional assume, na perspectiva dos entrevistados, uma função fundamentalmente correctiva e reparadora de alguns comportamentos e atitudes face ao trabalho menos conciliatórios com os objectivos perfilhados pelo topo gestionário. Com efeito, parece existir uma certa crença ao nível do MEF e dos chefes de secção entrevistados de que a formação, de natureza estratégica, contribuirá inevitavelmente para difundir os valores da empresa e para, a nível mais operacional, abrir o espírito dos trabalhadores às novas orientações emergentes, para efectuar uma "verdadeira revolução cultural" (conforme o Jornal 0 Ponto). No entanto, ao nível das práticas formativas, identificamos o peso significativo de uma formação que visa primeiramente a aquisição de competências técnicas/específicas (39,3\%) e em segundo e terceiro lugar, respectivamente, a aquisição de capacidades de adaptação às mudanças (24,8\%) e aquisição de competências gerais e relacionais $(23,9 \%)$ (conforme o Q uadro 2 ).

Q uadro 2. O bjectivos principais das acções de formação que frequentou na empresa

\begin{tabular}{l|c|c}
\hline O bjectivos principais & N & \% \\
\hline 1. Aquisição de competências técnicas (específicas) & 46 & 39,3 \\
2. Aquisição de capacidades de adaptação às mudanças & 29 & 24,8 \\
3. Aquisição de competências gerais e relacionais & 28 & 23,9 \\
4. Capacidade de definição de opções estratégicas da empresa & 14 & 12,0 \\
TOTAL & 117 & $100 \%$ \\
\hline
\end{tabular}

Fonte: Inquérito por questionário administrado a uma amostra de 131 trabalhadores da empresa E, no ano de 2001. 
Estes resultados muito voltados para o desempenho ao nível do posto de trabalho - adquirir novas competências ao nível do posto de trabalho $(63,4 \%)$ - parecem estar francamente associados ao aumento da eficiência e eficácia no trabalho (70,2\%) (conforme o Q uadro 3), aliás os dois objectivos da formação (proposta pela empresa) maioritariamente votados pelosinquiridos. E então constatamos que, na prática, os objectivos da formação ligados à cultura e identidades profissionais, constituem na perspectiva dos trabalhadores inquiridos, aqueles que a empresa menos valorizou.

Q uadro 3. M otivos da proposta de formação da empresa (o inquirido pode assinalar mais do que um item)

\begin{tabular}{l|l|l}
\hline Principais motivos da empresa & N & $\%$ \\
\hline 1. Adquirir novas competências ligadas ao posto de trabalho & 83 & 63,4 \\
2. Favorecer a resolução de um problema do meu serviço & 33 & 25,2 \\
3. Aceder a uma nova qualificação & 11 & 8,4 \\
4. Adquirir um diploma & - & - \\
5. Conhecer melhor a empresa & 5 & 3,8 \\
6. Favorecer um melhor espírito colectivo na empresa & 17 & 13,0 \\
7. Obter subsídios & 7 & 5,3 \\
8. Distinguir os melhores trabalhadores & 1 & 0,8 \\
9. Aumentar a fidelidade à empresa & 1 & 0,8 \\
10. Reforçar a imagem da empresa & 17 & 13,0 \\
11. Aumentar a eficiência e a eficácia no trabalho & 92 & 70,2 \\
\hline
\end{tabular}

Fonte: Inquérito por questionário administrado a uma amostra de 131 trabalhadores da empresa $\mathrm{E}$, no ano de 2001. 
4.4. A elaboração da política e do plano de formação: a reiteração de um modelo não participado e fechado

O processo de construção da política de formação obedece a um esquema muito semelhante ao identificado em outras empresas por nós estudadas. De acordo com os testemunhos situados ao nível da DRH e das chefias, o processo de elaboração ora começa com um plano provisório concebido no MEF e desce às chefias para que se pronunciem, ora inicia-se na base (chefias) sob a forma de elaboração de propostas (temas) e sobe ao M EF para a formulação final. Em qualquer dos casos, o que parece prevalecer é uma lógica de construção pouco participada e pouco reflectida por parte dos trabalhadores (por exemplo, cerca de $80 \%$ dos inquiridos refere nunca ter sido consultado sobre o plano de formação) e o predomínio do critério técnico (escolha das áreas temáticas prioritárias, de acordo com a natureza das funções) sobre todos os outros.

Por sua vez, os mecanismos de difusão da informação sobre a formação tendem a ser de índole mais informal (informação oral dada por um responsável, com 58,0\%), se bem que o mecanismo mais burocrático também seja utilizado com alguma frequência (distribuição de um documento escrito, com 44,3\%) (conforme o Quadro 4).

Q uadro 4. Conhecimento da existência de formação na empresa (o inquirido pode assinalar mais do que um item)

\begin{tabular}{l|c|c}
\hline \multicolumn{1}{c|}{ Meios } & N & $\%$ \\
\hline 1. Por um documento distribuído na empresa & 58 & 44,3 \\
2. Por informação oral dada por um responsável & 76 & 58,0 \\
3. Por conversas informais com outros colegas & 6 & 4,6 \\
4. Por outro meio & - & - \\
\hline
\end{tabular}

Fonte: Inquérito por questionário administrado a uma amostra de 131 trabalhadores da empresa $\mathrm{E}$, no ano de 2001. 
Q uanto ao modelo pedagógico de formação previsto, predomina o modelo escolar, centrado no seguimento do programa do formador $(45,8 \%)$, se bem que se recorra com alguma frequência à discussão colectiva $(34,4 \%)$, a trabalhos de grupo (32,1\%) - conforme o Quadro 5 - e à utilização de experiências profissionais anteriores (50\% - conforme o Q uadro 6).

Q uadro 5. Formas de animação das acções de formação (o inquirido pode assinalar mais do que um item)

\begin{tabular}{l|c|c}
\hline Formas de animação da última acção de formação & N & $\%$ \\
\hline 1. Discutir colectivamente um assunto & 45 & 34,4 \\
2. Realizar trabalhos de grupo & 42 & 32,1 \\
3. Apresentar práticas profissionais & 41 & 31,3 \\
4. Estudar um caso ou uma situação profissional & 20 & 15,3 \\
5. Seguir o programa dado pelo formador & 60 & 45,8 \\
\hline
\end{tabular}

Fonte: Inquérito por questionário administrado a uma amostra de 131 trabalhadores da empresa E, no ano de 2001.

Q uadro 6. U tilização das experiências profissionais

\begin{tabular}{l|c|c}
\hline Utilização & N & $\%$ \\
\hline 1. Não & 61 & 50,0 \\
2. Sim & 61 & 50,0 \\
TOTAL & 122 & $100 \%$ \\
\hline
\end{tabular}

Fonte: Inquérito por questionário administrado a uma amostra de 131 trabalhadores da empresa E, no ano de 2001. 
O Plano de Formação da empresa E encontra-se dividido em sete áreas temáticas distintas - línguas, gestão industrial, técnica, higiene e segurança, qualidade, especial secretariado e informática - onde constam os objectivos, o público-alvo, o número mínimo e máximo de participantes, a duração e o tipo de formador (interno ou externo). Trata-se de um documento que reflecte um modelo de formação fechado, construído em uma base tecnocrática cuja lógica organizativa está dependente do tema, isto é, de acordo com a especificidade do tema deduz-se qual o público que reúne mais condições para o frequentar. Relativamente aos modelos pedagógicos e aos locais da formação, não está prevista qualquer orientação.

Interessa, ainda, a título de confrontação com os dados previstos no plano de formação, referir que durante o ano de 1999 , apenas $28 \%$ dos trabalhadores participaram nas acções de formação, sobretudo internas, e com maior incidência nos quadros médiose intermédios (encarregados, contramestres e chefes de equipa). Por exemplo, os profissionais semiqualificados, não qualificadose praticantes/aprendizes, não participaram de qualquer tipo de formação na empresa (conforme Balanço Social de 1999).

4.5. As estratégias individuais na procura de formação: desmobilização e passividade

N este contexto empresarial contatamos a total inexistência de atitudes activas por parte dos trabalhadores, em geral, em relação à formação, ou seja, persiste ainda um quadro muito marcado pela ausência de iniciativas individuais ou colectivas por parte dos trabalhadores em relação à participação (sobretudo ao nível da concepção e planeamento) na política de formação da empresa. 0 envolvimento e a participação por parte de um sector muito reduzido dos trabalhadores (muito centrado nos chefes de secção) se encontra ainda muito encurralado numa estrutura e política organizativa da formação que estipula, a partir de cima, os momentos, os contextos, os actores e as metodologias da participação mais adequadas. 
Daqui decorre que a relação do conjunto dos trabalhadores com as políticas de formação (e utilizando a tipologia da participação de Lima, 1992) é de tipo essencialmente convergente (muito pouco crítica), passiva (aceitação comodista ou instrumental), muito formal e indirecta, no sentido de mediatizada pelos interesses e prioridades definidas pelo chefe de secção. Esta interpretação encontra alguma fundamentação nas respostas dos inquiridos relativamente à origem da última inscrição, em que se constata que cerca de $90 \%$ dos trabalhadores refere que a inscrição foi feita sob uma proposta da empresa. Podemos, então, concluir que a formação constitiu uma área mais ou menos externa aos trabalhadores, não sendo ainda perspectivada como um direito inerente à condição de trabalhador, mas sim como um dever exclusivamente da responsabilidade da empresa.

4.6. O s efeitos das formações realizadas: o ciclo encerra com a proclamação da eficácia e da eficiência no trabalho

Q uando confrontamos os trabalhadores inquiridos com uma série de proposições sobre os efeitos da formação, constatamos, uma vez mais, o peso significativo atribuído às dimensões técnicas (uma melhoria do meu trabalho quotidiano), às dimensões de índole organizativa (melhor percepção da empresa e dos seus objectivos) e, em terceiro lugar, a factores de natureza individual (uma experiência individual interessante). No que concerne às dimensões mais dirigidas ao desenvolvimento dos direitos cívico-laborais, detectamos a sua total irrelevância como resultado da formação, confirmando algumas das nossas hipóteses que apontavam para uma concepção de formação muito arreigada aos valores tecnocráticos e economicistas que subjazem ao projecto estratégico das empresas. De referir, por fim, que as proposições relativas à cultura e identidades profissionais, foram também consideradas pouco importantes como resultado ou contribuição da formação. 
Q uadro 7. Resultados (em percentagens) da última formação frequentada (1= M ínimo e 5= M áximo)

\begin{tabular}{|c|c|c|c|c|c|}
\hline Resultados da formação & 1 & 2 & 3 & 4 & 5 \\
\hline Novas competências técnicas $(N=120)$ & 13,3 & 10,8 & 30,0 & 32,5 & 13,3 \\
\hline $\begin{array}{l}\text { Novas atitudes profissionais (novas formas de se relacionar com } \\
\text { os outros) }(\mathrm{N}=115)\end{array}$ & 25,2 & 11,3 & 29,6 & 27,0 & 7,0 \\
\hline $\begin{array}{l}\text { Consciência mais viva dos problemas enfrentados pelos traba- } \\
\text { lhadores }(\mathrm{N}=115)\end{array}$ & 25,2 & 11,3 & 27,0 & 26,1 & 10,4 \\
\hline Uma visão mais clara da minha função profissional $(\mathrm{N}=117)$ & 14,5 & 14,5 & 19,7 & 34,2 & 17,1 \\
\hline Um maior poder reivindicativo $(\mathrm{N}=111)$ & 47,7 & 21,6 & 18,0 & 8,1 & 4,5 \\
\hline Resistir mais a injustiças dentro da empresa $(\mathrm{N}=111)$ & 49,5 & 16,2 & 20,7 & 11,7 & 1,8 \\
\hline Um melhor conhecimento do trabalho dos outros $(\mathrm{N}=112)$ & 15,2 & 12,5 & 35,7 & 23,2 & 13,4 \\
\hline Compreender melhor os objectivos da empresa $(\mathrm{N}=117)$ & 9,4 & 8,5 & 23,9 & 31,6 & 26,5 \\
\hline Aceitar melhor a ordem e a hierarquia (chefias) $(\mathrm{N}=111)$ & 27,0 & 19,8 & 34,2 & 9,9 & 9,0 \\
\hline $\begin{array}{l}\text { Possibilidade de realizar novos projectos com outros colegas } \\
(\mathrm{N}=108)\end{array}$ & 21,3 & 13,9 & 33,3 & 22,2 & 9,3 \\
\hline Estar mais alerta em relação à insegurança no emprego $(\mathrm{N}=110)$ & 33,6 & 18,2 & 21,8 & 16,4 & 10,0 \\
\hline Estar mais atento aos meus direitos na empresa $(\mathrm{N}=110)$ & 45,5 & 18,2 & 18,2 & 10,0 & 8,2 \\
\hline Ter mais interesse pelos projectos da empresa $(\mathrm{N}=113)$ & 12,4 & 16,8 & 23,0 & 28,3 & 19,5 \\
\hline Uma melhor compreensão das mudanças na empresa $(\mathrm{N}=111)$ & 11,7 & 16,2 & 24,3 & 31,5 & 16,2 \\
\hline $\begin{array}{l}\text { Um interesse para dizer aos outros o que aprendi nesta formação } \\
(\mathrm{N}=114)\end{array}$ & 16,7 & 13,2 & 31,6 & 25,4 & 13,2 \\
\hline Uma experiência pessoal interessante $(\mathrm{N}=114)$ & 14,0 & 8,8 & 21,1 & 29,8 & 26,3 \\
\hline $\begin{array}{l}\text { A capacidade de exercer uma função de orientador/tutor para } \\
\text { outras pessoas }(\mathrm{N}=110)\end{array}$ & 28,25 & 16,4 & 30,9 & 16,4 & 8,2 \\
\hline $\begin{array}{l}\text { Uma oportunidade para relembrar ou aprofundar formações an- } \\
\text { teriores }(\mathrm{N}=110)\end{array}$ & 19,1 & 18,2 & 37,3 & 17,3 & 8,2 \\
\hline Uma melhoria do meu trabalho no dia-a-dia $(N=115)$ & 6,1 & 11,3 & 18,3 & 33,9 & 30,4 \\
\hline Ser mais considerado na empresa $(N=112)$ & 32,1 & 21,4 & 27,7 & 7,1 & 11,6 \\
\hline $\begin{array}{l}\text { Uma melhor compreensão das possibilidades de subir na carrei- } \\
\text { ra }(N=110)\end{array}$ & 43,6 & 20,0 & 20,0 & 8,2 & 8,2 \\
\hline Maior capacidade para trabalhar sem ser controlado $(N=113)$ & 32,7 & 12,4 & 21,2 & 23,0 & 10,6 \\
\hline Uma maior lealdade à empresa $(\mathrm{N}=113)$ & 25,7 & 15,0 & 30,1 & 12,4 & 16,8 \\
\hline $\begin{array}{l}\text { Um reforço dos laços de amizade com trabalhadores do mesmo } \\
\text { sector/serviço }(\mathrm{N}=112)\end{array}$ & 27,7 & 11,6 & 33,0 & 17,0 & 10,7 \\
\hline
\end{tabular}

Fonte: Inquérito por questionário administrado a uma amostra de 131 trabalhadores da empresa E, no ano de 2001.

(1 - Resultados mínimos/quase inexistentes; 2 - Resultados diminutos; 3 - Resultados suficientes; 4 - Resultados bons/satisfatórios; 5 - Resultados excelentes) 


\section{N otas finais: a dessacralização da formação e a sua reposição nos contextos culturais de produção}

Após análise de todos os dados concernentes à empresa $\mathrm{E}$, podemos avançar algumas tendências significativas acerca das políticas e práticas de formação e sua articulação com a cultura e as identidades organizacionais. Assim, no que se refere aos valores, princípios e orientações fundamentais da empresa identificamos uma certa descontinuidade entre um discurso político, situado no topo estratégico, que defende e procura imprimir a todos os patamares da empresa, os valores da excelência, da qualidade, da eficácia e da eficiência, como os pilares axiológicos da toda a organização e, por outro lado, a constatação da coexistência de múltiplas culturas e identidades profissionais, ao nível dos Departamentos da empresa, assentes em lógicas e padrões de trabalho frequentemente antagónicas e conflitantes com as ditadas superiormente.

A política de formação do grupo, pelo menos do ponto de vista formal, reflecte como preocupação fundamental ao tentar solucionar os problemas advindos da dicotomia entre a cultura da gerência e as culturas de execução, mas ao nível da definição dos seus objectivos estratégicos e operacionais de formação esbarra em outro tipo de prioridades, nomeadamente as prioridades gestionárias de eficácia, competitividade, excelência, qualidade. E são estas prioridades que vão, de facto, orientar, os objectivos para a formação, ao torná-la essencialmente um mecanismo reactivo, no sentido de resolver problemas concretos ao nível do posto de trabalho, como se pode constatar nas respostas dos inquiridos, muito orientadas para os itens que valorizam 0 carácter utilitário, pragmático e tecnicista da formação.

No que concerne ao processo de construção da política e do plano de formação verificamos que obedeceu a uma lógica vertical e centralizada. A idéia de construção participada e democrática do plano tem-se traduzido na prática pela auscultação realizada a grupos de informadores privilegiados, 
nomeadamente os Chefes de Secção, mas sempre partindo de uma filosofia centrada mais na recolha passiva do que na participação activa, exigindo o envolvimento e o accionamento de estratégias mais inspiradas nas metodologias participativas. Sintomático desta leitura são as respostas dos trabalhadores às questões relacionadas com os mecanismos de difusão da informação e acerca do modo pelo qual foram consultad os para a elaboração do plano de formação. Em primeiro lugar constatamosa hegemonia de um modelo de circulação da informação de tipo vertical e descendente, optando-se ora por estratégias mais informais (por exemplo informação verbal dada por um responsável pela secção) ou por modalidades mais burocráticas (por exemplo, por um documento escrito). Em segundo lugar, a maioria dos trabalhadores inquiridos refere não terem sido consultados, em momento algum, aquando da elaboração do plano da formação.

A estrutura dos planos de formação está congruente com os princípios norteadores da política de formação deste grupo. Ao privilegiar uma estrutura fechada, no sentido de obedecer a um formato pré-definido, sequencial e determinista, uma vez mais nos remete para a defesa da hipótese de que a concepção da formação emerge completamente divorciada das especificidades culturais e identitárias das empresas. E este modelo de formação uniforme e pronto a vestir acaba por resistir a potenciais remodelações ao longo de todo o processo de implementação, na medida em que assenta nem uma filosofia de ruptura entre um sector que concebe e a massa que executa.

Face a este quadro, podemos admitir que estão criadas as condições propícias à construção de uma certa cultura de acomodação e de expectativa por parte dos trabalhadores em relação à formação, o que é comprovado pela resposta à questão sobre a origem da inscrição da última acção de formação frequentada, que aponta para um peso maioritário do item proposta da empresa. Além disso, constatamos ainda que esta ausência de iniciativa dos trabalhadores poderá também estar associada à sua não cola- 
boração na definição de critérios de distribuição dos formandos pelas acções de formação. 0 critério prevalecente - o económico - exclui todas as possibilidades de se atender à construção dos públicos-alvos na base de outros objectivos, como por exemplo, os etários, os identitários, etc.

Por fim, ao analisarmos os efeitos da formação, voltamos a corroborar a hipótese de que aquela está orientada fundamentalmente para uma meIhor apreensão da organização do trabalho e para um melhor desempenho da função ligada directamente ao posto de trabalho. Por sua vez, parece ficar definitivamente abandonada a ideia de a formação ministrada poder contribuir para uma socialização ao nível de determinados valores morais, éticos e deontológicos, já que as respectivas proposições foram consideradas pelos inquiridos como as menos importantes.

O que parece prevalecer nesta empresa é uma espécie de apologia dos princípios da formação, embora assente em lógicas externas às especificidades da organização. Isto é, parece haver uma certa consciência e mesmo reconhecimento da importância dos factores culturais e organizacionais para a formulação da política estratégica das empresas e, mais especificamente para a construção da política de formação, mas parece estar ausente todo um capital teórico, investigativo e prático susceptível de criar uma orientação formativa integrada e coerente com os pontos de partida diagnosticados. Se assim fosse, a opção teria passado pela criação de um plano de formação mais participado, a constituição dos públicos alvos teria obedecido a critérios minuciosamente investigados, os formatos pedagógicos contemplariam uma maior diversidade de estratégias. Apostarse-ia, no fundo, em uma espécie de projecto de formação flexível que visibilizasse mais uma dinâmica construtiva e reconstrutiva de subprojectos que, de facto, se articulassem melhor com as distintas culturas e identidades profissionais em presença. 
Referências

ALVESSO N, Mats \& BERG, Per O lof. Corporate Culture and Organizational Symbolism. An 0 verview. N ew York: Walter de Gruyter, 1992.

ALVESSO N, M ats. Understanding Organizational Culture. London: Sage Publications, 2002.

BARLEY, Stephen. Semiotics and the Study of Occupational and Organizational Culture. In: FROST, Peter J. et al. (Eds.). Refraiming O rganizational Culture. London: Sage Publications, pp. 39-59, 1991.

DUBAR, Claude. La socialization. Construction des Identités Sociales et Professionnelles. Paris: Armand Colin, 1991.

DUBAR, Claude (1985). M utations Technologiques et Formation: Discours, Réalités, Paradoxes. Éducation Permanente, no 81, pp. 37-54, 1985.

DUBAR, Claude. Formação, Trabalho e Identidades Profissionais. In: CANÁRIO, Rui (O rg.). Formação e Situações de Trabalho. Porto: Porto Editora, pp. 43-52, 1997.

ESTÊVÃO, Carlos A. Vilar. Políticas de Formação e Cidadania O rganizacional. Revista de Educação, Vol. III, no 1, pp. 213-220, 1999.

ESTÊVÃO, CarlosA. Vilar (Coord.). Training Policies and Practices in O rganizations. Relatório de Investigação. Braga: Centro de Estudos em Educação e Psicologia da Universidade do Minho, 2002.

FRO ST, Peter J. et al. (Eds.). Reframing O rganizational Culture. London: Sage Publications, 1991.

GO MES, Adelino. Mudança O rganizacional: Mudar a Cultura ou Mudar de Estratégia?. Análise Psicológica, Vol. XII (1), pp. 15-30, 1994.

GREGORY, Kathleen L. Native-View Paradigms: Multiple Cultures and Cultures Conflicts in O rganizations. Administrative Science Q uartely, no 28, pp. 359-376, 1983.

LESNE, M. \& MYNVIELLE, Y. Formation et Socialisation. Paris: Paideia, 1990.

LIMA, Licínio, C. M odernização, Racionalização e 0 ptimização: Perspectivas N eoTaylorianas na O rganização e Administração da Educação. Cadernos de Ciências Sociais, nํㅜ 14, pp. 119-139, 1994. 
LOU IS, Meryl R. An Investigator's Guide to Workplace Culture. In: FRO ST, Peter J. et al. (Eds.). Organizational Culture. London: Sage, pp. 73-93, 1985.

MAANEN, John Van (1991). The Smile Factory: Work at Disneyland. In: FRO ST, Peter J. et al. (Eds.). Refraiming O rganizational Culture. London: Sage Publications, pp. 58-76, 1991.

MARTIN, Joanne. Cultures in O rganizations. Three Perspectives. N ew York, Oxford, O xford U niversity Press; London: Sage Publications, pp. 58-76, 1992.

MARTIN, Joanne \& MEYERSO N, Debra. O rganizational Culture and the Denial, Channeling and Acknowledgement of Ambiguity. In: PO NDY, L. R., BO LAND, R. J., Jr., THO M AS, H. (Eds.). Managing Ambiguity and Change. New York: John Wiley, pp. 93-125, 1988.

MARTIN, Joanne. O rganizational Culture. Mapping the Terrain. London: Sage Publications, 2002.MCDO NALD, Peggy. The Los Angeles Olympic O rganizing Committee: Developing O rganizational Culture in the Short Run. In: FROST, Peter J. et al. (Eds.). Refraiming O rganizational Culture. London: Sage Publications, pp. 26-38, 1991.

OTTAW AY, Richard. Mudança de Cultura Numa O rganização, Análise Psicológica, Vol. II (2/3), pp. 315-320, 1982.

OUCHI, William G. Teoria Z. Como as Empresas Podem Enfrentar o Desafio Japonês. São Paulo: Nobel, 1986.

PETERS, T. J. \& W ATERM AN, R. H. In Search of Excellence ( $N$ a Senda da Excelência). Lisboa: Publicações Dom Quixote, 1987.

ROSEN, Michael. Breakfast at Spiro's: Dramaturgy and Dominance. In: FRO ST, Peter J. et al. (Eds.). Refraiming O rganizational Culture. London: Sage Publications, pp. 77-89, 1991.

SAIN SAULIEU, Renaud. Sociologie de L'organizacion et de L'entreprise. Paris: Presses de la Fondation N ationale des Sciences Politiques et Dalloz, 1987.

SAINSAU LIEU, Renaud. L'identité au Travail. Paris: Presses de la Fondation Nationale des Sciences Politiques, 1988.

SCHEIN, Edgar. Organizational Culture and Leadership. São Francisco: JosseyBass Publishers, 1985. 
SCHEIN, Edgar. The Role of the Founder in the Creation of O rganizational Culture. In: FRO ST, Peter J. et al. (Eds.). Refraiming O rganizational Culture. London: Sage Publications, pp. 14-25, 1991.

SM IRCICH, Linda. Concepts of Culture and O rganizational Analysis, Administrative Science Q uarterly, no 28, pp.339-358, 1983.

TO RRES, Leonor L. Cultura O rganizacional Escolar: Representações dos Professores Numa Escola Portuguesa. O eiras: Celta Editora, 1997.

TO RRES, Leonor L. A Cultura O rganizacional na (Re)conceptualização da Formação em Contextos O rganizacionais, Cadernos de Ciências Sociais, n-s 21-22, pp. 119-150, 2001.

TO RRES, Leonor L. Cultura O rganizacional em Contexto Educativo. Sedimentos Culturais e Processos de Construção do Simbólico Numa Escola Secundária. Braga: CIED/U niversidade do Minho, 2004. 


\section{Resumo}

Contrariando as tendências mais recentes que teimam em estabelecer relações lineares e unidireccionais entre as problemáticas da cultura e da formação em contexto de trabalho, propomos neste artigo um raciocínio invertido assente na discussão das mútuas imbricações entre estes dois campos do saber, designadamente a problematização das múltiplas formas e processos de formação por referência às especificidades culturais e simbólicas das organizações de trabaIho. Para ilustrar a pertinência desta proposta recorremos a um conjunto de dados empíricos que recolhemos num dos seis estudos de caso desenvolvidos no âmbito de um projecto de investigação transnacional, submetendo este corpus empírico a uma análise interpretativa e a um confronto com as nossas hipóteses teóricas.

Palavras-chave: cultura organizacional; abordagens simbólicas; formação profissional; formação no local de trabalho; formação experiencial; sociologia das organizações. 


\section{ARTIGOS}

ARTICLES

\section{(Re)thinking culture and education within the work context: trends, perspectives and possibilities of articulation}

\section{Leonor Maria de Lima Torres}

Contrary to the latest trends, which insist on establishing linear and unidirectional relationships between the problematics of culture and workplace education, this work proposes an inverted reasoning based on the discussion of mutual imbrications between these two fields of knowledge, namely, the problematization of the multiple education forms and procedures with reference to the cultural and symbolic specificities of the organizations of work. To illustrate the relevance of this proposal, the author employs a set of empirical data collected in one of the six case studies developed as part of a transnational research project, subjecting this empirical corpus to an interpretative analysis and a confrontation with his own theoretical assumptions.

Keywords: organizational culture, symbolic approaches, professional education, workplace education, experiential education, sociology of organizations. 